\title{
PSO-PD Fuzzy Control of Distillation Column
}

\author{
Yousif Al-Dunainaw \\ Electronic and Computer Engineering \\ Brunel University London, UK \\ Yousif.al-dunainawi@brunel.ac.uk
}

\author{
Maysam F. Abbod \\ Electronic and Computer Engineering \\ Brunel University London, UK \\ maysam.abbod@brunel.ac.uk
}

\begin{abstract}
In this paper, PD-fuzzy logic control has been designed to control product compositions of distillation column. Manual and Particle Swarm Optimisation (PSO) procedures have been applied to tune scaling factors of the controller. Simulation is carried out to minimize the Integral of Square Error (ISE). System behaviour analysis shows very good performance and fast response.
\end{abstract}

Keywords-fuzzy logic control; particle swarm optimisation; distillation column

\section{INTRODUCTION}

Industrial processes have developed during the recent decades into very complex and remarkably integrated systems, because of the worldwide ambition for more reliable fulfilment of high product quality, more efficient use of energy, tighter safety and environmental regulations. These strict needs naturally make additional difficult and more challenging control problems for industrial process control engineers. Nowadays, difficulties require more effective solutions than can be done by only conventional techniques [1].

However many control schemes have emerged, linear models are regularly used although many chemical processes represent major nonlinear performance. Acceptable performance, in general, is achieved over a narrow operating range, nonetheless when a wide range of process operations with close-fitting conditions on product composition is in demand. Thus, the nonlinearities become more critical and control performance is sacrificed [2].

Linear controllers such as PI, PD and PID have restrictions in system response to variations in operating points, and a poor treatment of system nonlinearities [3]. These limitations could be overcome with fuzzy logic controllers due to their capability of handling nonlinearities and uncertainties of systems, and can be established from heuristic knowledge, 1 . without requisite of a precise description of the controlled 2 . system [4]. Consequently, many researches have been 3 . implemented by fuzzy strategies for distillation process [5-7]. 4.

This paper discusses the findings of the use of PD-like5. fuzzy logic controller for distillation column using particle6. swarm optimisation PSO as tuner to choose the optimal values of scaling factors (gains).

\section{DISTILLATION PROCESS}

Distillation, doubtlessly, is the most essential and vital process in separation and purification. Almost all petroleum refineries, petrochemical and chemical plants around the world use this technology to separate mixtures into their individual components [7].

Distillation is reported as an energy intensive process. A report from the US Department of Energy has indicated that distillation is the largest consumer of energy in the chemical industry; typically, it accounts for $40 \%$ of the energy consumed by petrochemical plant [8]. In spite of its "thirst" to energy, distillation persists to be a widely used process for separation. Efficiently, operating these columns requires a high degree of automatic control [9].

The distillation column used in this paper is a binary type as shown in Fig. 1 which enters the feed tray as a continuous stream with flow rate $\mathrm{F}$, normally at the middle, obtaining both a distillate product with composition $\mathrm{xD}$ (mole fraction) and a bottom product with composition $\mathrm{xB}$ (mole fraction).

The column consists of $\mathrm{N}=20$ trays. The overhead vapour is totally condensed in a water-cooled condenser (tray $\mathrm{N}+1$ ) which is open at atmospheric pressure. The process inputs available for control purposes are the vapour which flows from boiler $\mathrm{V}(\mathrm{kmol} / \mathrm{min})$ and the reflux flow rate $\mathrm{L}$ $(\mathrm{kmol} / \mathrm{min})$. Liquid heights in the column bottom and the receiver drum (tray 0) dynamics are not considered for control since flow dynamics are significantly faster than composition dynamics and pressure control is not required meanwhile the condenser is opened to atmospheric pressure.

\section{MODELLING OF DISTILLATION COLUMN}

The dynamic model can be simplified under the following assumptions:

Constant pressure (atmosphere pressure).

Binary mixture.

Constant relative volatility.

No vapour hold up.

Constant liquid hold up on all trays.

Perfect mixing and equilibrium for vapour-liquid on all stages. 


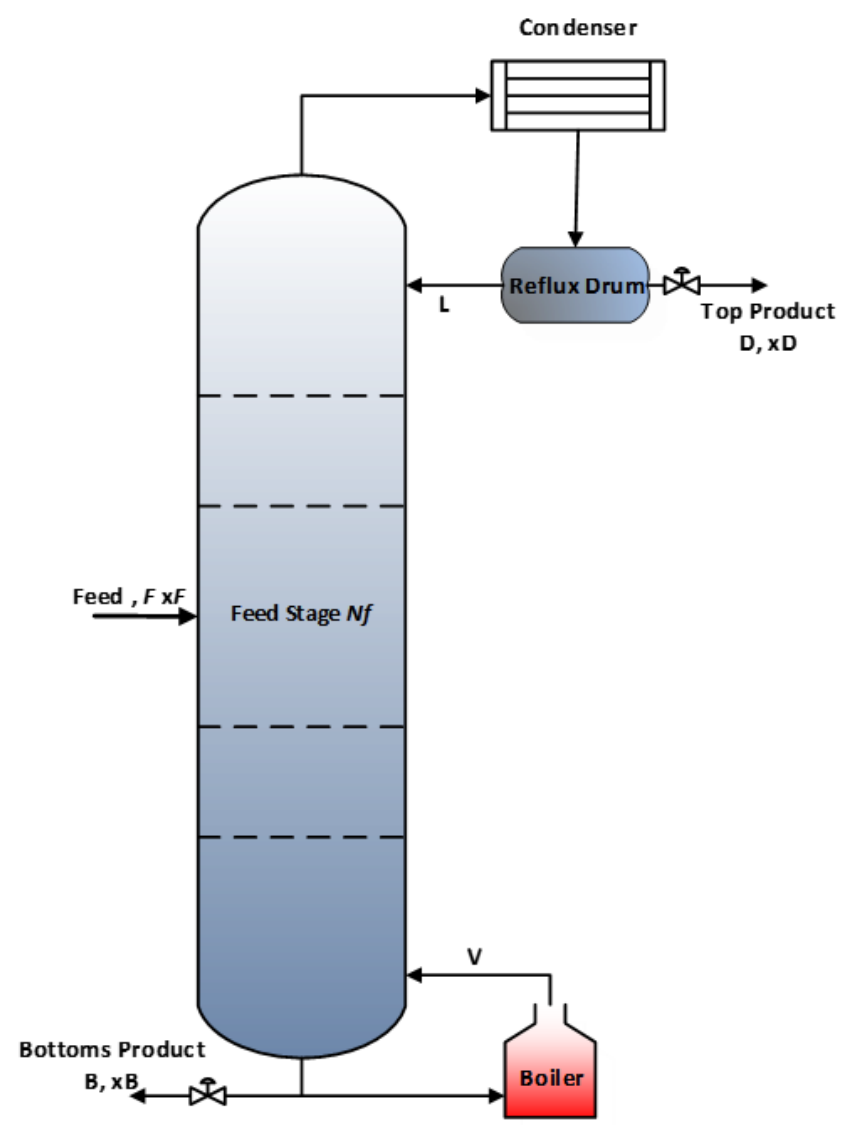

Fig. 1. Schematic diagram of binary distillation column.

So, the model can be expressed mathematically by the following equations:

On each tray (excluding reboiler, feed and condenser stage):

$$
M_{i} \frac{d x_{i}}{d t}=L_{i+1} x_{i+1}+V_{i-1} y_{i-1}-L_{i} x_{i}-V_{i} y_{i} \ldots 1
$$

Above feed stage $i=N_{F}+1$;

$$
M_{i} \frac{d x_{i}}{d t}=L_{i+1} x_{i+1}+V_{i-1} y_{i-1}-L_{i} x_{i}-V_{i} y_{i}+F_{v} y_{F} \ldots 2
$$

Below feed stage, $i=N_{F}$ :

$$
M_{i} \frac{d x_{i}}{d t}=L_{i+1} x_{i+1}+V_{i-1} y_{i-1}-L_{i} x_{i}-V_{i} y_{i}+F_{L} x_{F} \ldots 3
$$

At the reboiler and column base, $i=1, x_{i}=x_{B}$ :

$$
M_{B} \frac{d x_{i}}{d t}=L_{i+1} x_{i+1}-V_{i} y_{i}+B x_{B} \ldots 4
$$

At condenser, $i=N+1, x_{D}=x_{N+1}$;

$$
M_{D} \frac{d x_{D}}{d t}=V_{i-1} y_{i-1}-L_{i} x_{D}-D x_{D} \ldots 5
$$

Vapour-liquid equilibrium relationship for each tray [10]:

$$
y_{i}=\frac{\propto x_{i}}{1+(\alpha-1) x_{i}} \ldots 6
$$

Flow rate at constant molar flow:

Above feed stage: $L_{i}=L, \quad V_{i}=V+F_{v} \quad \ldots 7$

At or below feed stage: $L_{i}=L+F_{L}, \quad V_{i}=V \ldots 8$

Since $F_{l}=q_{F} * F, \quad F_{v}=F+F_{L} \ldots 9$

Constant holdup for both condenser and reboiler

Reboiler: $\quad B=L+F_{L}-V \ldots 9$

Condenser: $\quad D=V+F_{V}-L \ldots 10$

Feed compositions $x_{F}$ and $y_{F}$ are found from flash equation as:

$$
F_{z F}=F_{L} * x_{F}-F_{V} * y_{F} \ldots 11
$$

Variable Description:

$\mathrm{N}$ : Number of stages

i: Number of trays

F: Feed flow rate

$\mathrm{Z}_{\mathrm{F}}$ : Mole fraction of light component in the mixture

$\mathrm{q}_{\mathrm{F}}$ : Mole fraction of liquid in the mixture

D: Distillate flow rate

V: Boilup

L: Reflux flow rate

B: Bottom flow rate

M: Tray hold up

$\mathrm{M}_{\mathrm{D}}$ : Condenser hold up

$\mathrm{M}_{\mathrm{B}}$ Reboiler hold up

$\mathrm{x}$ : Mole fraction of light component in liquid

$y$ : Mole fraction of light component in vapour

$\mathrm{x}_{\mathrm{D}}$ : Distillate composition

$\mathrm{x}_{\mathrm{B} \text { : Bottoms composition }}$

$\alpha$ : Relative volatility

\section{FUZZY LOGIC CONTROL}

A fuzzy controller transforms a linguistic control strategy into automatic capabilities for managing the nonlinearities and uncertainties of the distillation column system. The aim of this control system is to make product compositions as close to the desired ones as possible. The proposed fuzzy controllers have the structure shown in Fig. 2. Mamdani inference and the centroid defuzzification mechanisms are applied. The universe of discourse of the inputs and the output are normalized in the interval $[-1,1]$. Thus, actual system values are converted through scaling factors (gains). Seven Gaussian membership functions have been defined for each input, as shown in Fig. 3. Linguistic expressions given to these fuzzy sets are positive big $\mathrm{PB}$, positive medium PM, positive small PS, positive negative, zero ZE, negative small NS, negative medium NM and negative big NB. The heuristic fuzzy rule base for distillation column controller is shown in Table I and Fig. 2. These demonstrate rules of the type if-and-then based on error and change in error. The Gaussian membership functions were applied for inputs and output of fuzzy controller. Gaussian membership function is defined as:

$$
\gamma(x)=e^{\left[\frac{-(x-c)^{2}}{\alpha}\right]} \ldots 12
$$

where $\mathrm{c}$ and $\alpha$ mean the deviation of a Gaussian membership function, respectively. The resulting fuzzy set must be converted to a signal that can be sent to the process as a control input. Centroid of area has been used here for defuzzification. Even though fuzzy logic allows for the conception of simple control algorithms, the tuning of these fuzzy controllers is a more difficult and sophisticated procedure than that of conventional ones. This is because of the membership functions and inference mechanisms are expressed by a large number of parameters [11].

There are many approaches which have been proposed to tune the fuzzy controllers by adjusting membership functions and/or scaling factors [12]. Due to their responsibility of input-output mapping to the discourse universes, scaling 
factors have a major influence on the controller' $\mathrm{s}$ performance. Therefore, adjusting of these parameters is the most commonly used technique for tuning fuzzy controllers [13] and is not usually straightforward, methods such trial and error could be time consuming [14]. Remarkably, bio-inspired intelligence approaches have been applied in recent years for tuning fuzzy controllers [15].

\section{PARTICLE SWARM OPTIMISATION (PSO)}

PSO algorithm was proposed by Kennedy and Eberhart by mimicking social behaviour of birds flock in 1995 [16] and 2001 [17] . In PSO procedure, all the agents (particles) are positioned at a random place and are supposed to change randomly in a defined direction in the search space. Each particle's direction is then changed steadily to assert to move along the direction of its best previous positions to discover even a new better position with respect to objective function (fitness). The initial particle's velocity and position are selected randomly and updated by the following equation:

$V c_{i+1}=w V_{i}+C 1 R 1 \times\left(P b_{i}-x_{i}\right)+C 2 R 2 \times\left(G b-x_{i}\right) \ldots 13$
$x_{i+1}=x_{i}+V c_{i+1} \quad . .14$

where:

$V c$ : velocity of the particle.

$x:$ position of the particle.

$R 1, R 2$ : random positive numbers between $(0,1)$.

$C 1, C 2$ : constants.

$w:$ Weight.

Eq. 1 is used to compute the new velocity of particle according to its preceding velocity and the distances of its current position from its own best position $(\mathrm{Pb})$ and the global best position $(G B)$. Then the particle moves to a new position according to Eq. 2. The performance of each particle is measured according to a pre-defined objective function (performance index).

\section{RESULTS AND ANALYSIS}

In the present research, two controllers have been applied with different configurations, manually tuned PD-fuzzy logic and PD-fuzzy logic tuned by PSO of distillation column. The quantitative criteria for measuring control performance is chosen as steady state error and integral of square error (ISE) as describe in the following equation:

$I S E=\int_{0}^{\infty} e(t)^{2} d t$

where $e$ is the error between the desired value and output of the distillation column (product compositions).

PSO used to find the optimal values of scaling factors (gains) of PD-fuzzy controllers as shown in Fig. 3.

It is clear that PD-PSO fuzzy controller shows more robustness and has small steady state error as well as ISE than that tuned with manually.

TABLE I.

UZZY RULE-BASE TABLE

\begin{tabular}{|c|c|c|c|c|c|c|c|}
\hline TABI TABLE III. & & & & Errol & & & \\
\hline $\begin{array}{c}\text { OUTPU } \\
\mathrm{T}\end{array}$ & $\begin{array}{l}\mathrm{N} \\
\mathrm{B}\end{array}$ & $\begin{array}{l}\mathrm{N} \\
\mathrm{M}\end{array}$ & NS & SS & PS & PM & PB \\
\hline NB & SS & NS & $\begin{array}{l}\mathrm{N} \\
\mathrm{M}\end{array}$ & $\begin{array}{l}\mathrm{N} \\
\mathrm{M}\end{array}$ & NB & NB & NB \\
\hline $\mathrm{NM}$ & PS & SS & NS & $\begin{array}{l}\mathrm{N} \\
\mathrm{M}\end{array}$ & $\begin{array}{l}\mathrm{N} \\
\mathrm{M}\end{array}$ & NB & NB \\
\hline
\end{tabular}

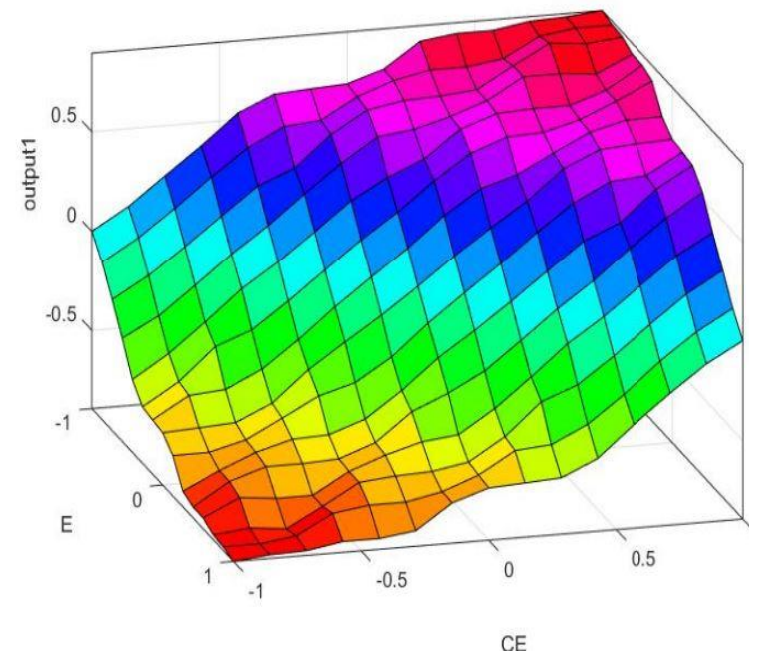

Fig. 2 Fuzzy control surface.

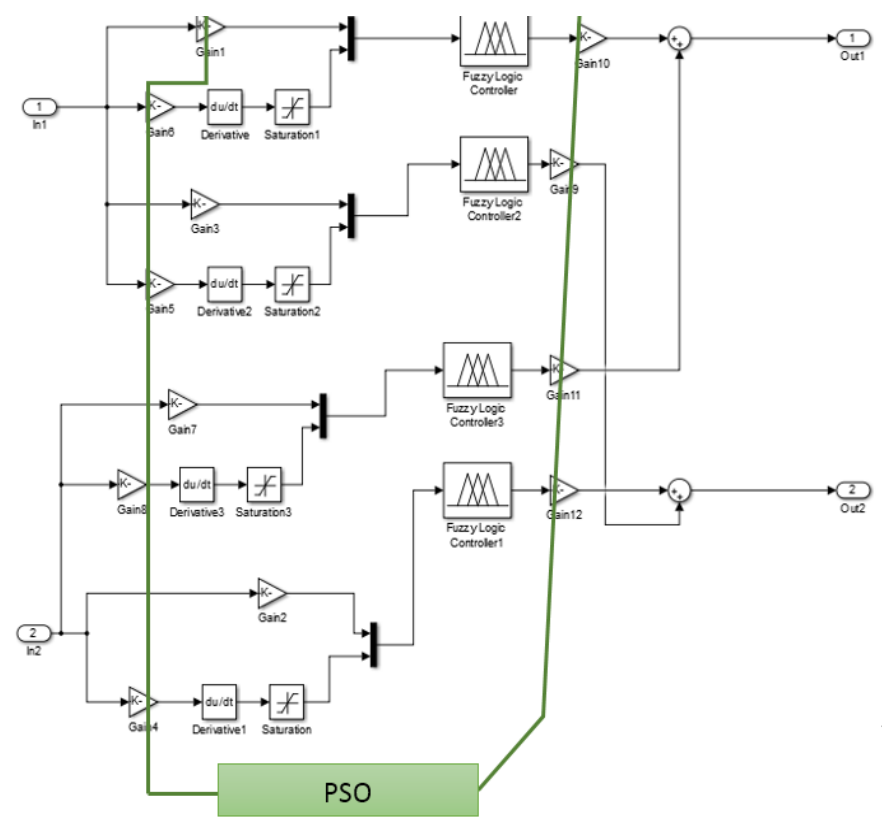

Fig. 3. PSO-tuned PD-fuzzy logic control configuration.

\begin{tabular}{c|ccccccr|}
\hline NS & P & PS & SS & NS & N & N & NB \\
SS & P & PM & P & S & N & N & N
\end{tabular}


convergence to the desired responses is achieved after the adaptation of the control output as shown in Fig. 5. This result gives an indication that this PD-fuzzy logic controller, trained by the PSO technique, has the ability to cope with external disturbances.

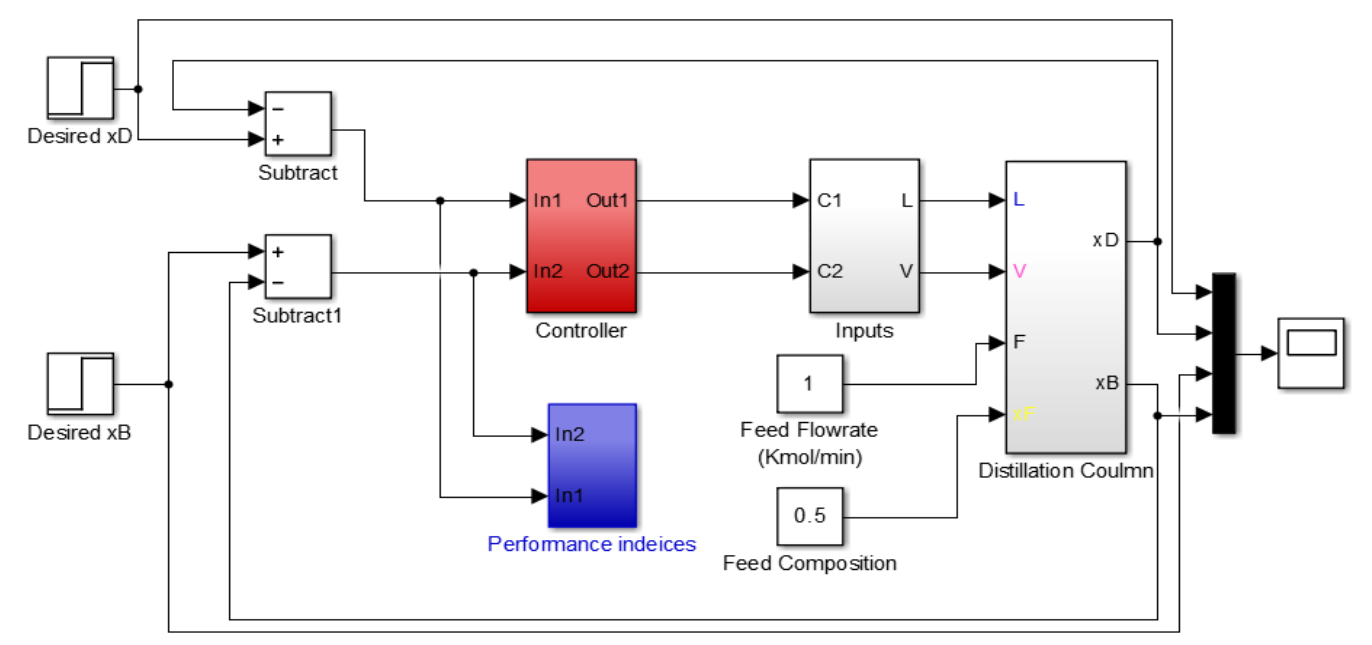

Fig.4. MATLB/Simulink model of control of distillation column.

PB \begin{tabular}{|lllllll}
$\mathrm{PB}$ & $\mathrm{PB}$ & $\mathrm{PB}$ & $\mathrm{PM}$ & $\mathrm{PM}$ & $\mathrm{PS}$ & $\mathrm{SS}$ \\
\end{tabular}

TABLE IV.

CONTROL PERFORMANCE COMPARISON

\begin{tabular}{|c|c|c|c|c|}
\hline \multirow{2}{*}{$\begin{array}{c}\text { Tuning } \\
\text { type }\end{array}$} & \multicolumn{2}{|c|}{ ISE } & \multicolumn{2}{c|}{ Steady state error } \\
\cline { 2 - 5 } & $\mathrm{xD}$ & $\mathrm{xB}$ & $\mathrm{xD}$ & $\mathrm{xB}$ \\
\hline $\begin{array}{c}\text { Manuall } \\
\mathrm{y}\end{array}$ & $\begin{array}{c}7.11 \times 10^{-} \\
4\end{array}$ & $\begin{array}{c}2.06 \times 10^{-} \\
3\end{array}$ & 0.0021 & 0.0012 \\
\hline $\mathrm{PSO}$ & $\begin{array}{c}1.73 \times 10^{-} \\
4\end{array}$ & $\begin{array}{c}3.83 \times 10^{-} \\
4\end{array}$ & $\begin{array}{c}6.01 \times 10^{-} \\
4\end{array}$ & $8.2 \times 10^{-4}$ \\
\hline
\end{tabular}

In order to demonstrate the robustness of PSO-tuned fuzzy logic controller, this controller has been examined more with different set points as shown in Fig. 5:

1. Fixed-step input for both set points.

2. Asynchronous changed-step input for both set points.

Simple set points have been addressed in the first configuration with fixed-step for both distillate composition with ( $\mathrm{xD}=0.99$ mole fraction) and bottom composition with $(\mathrm{xB}=0.09$ mole fraction). The controller shows very good performance and fast response to the desired inputs. While, the second configuration is done to establish how robust this controller is to change in both set points at different time to act as external disturbances. The first change is applied at the time (30 min), whereas the second one is applied at the time (60 min).

It can be noticed that the control actions of the PSOtuned fuzzy logic controller is adapted to exclude the effect of the external disturbances, where the

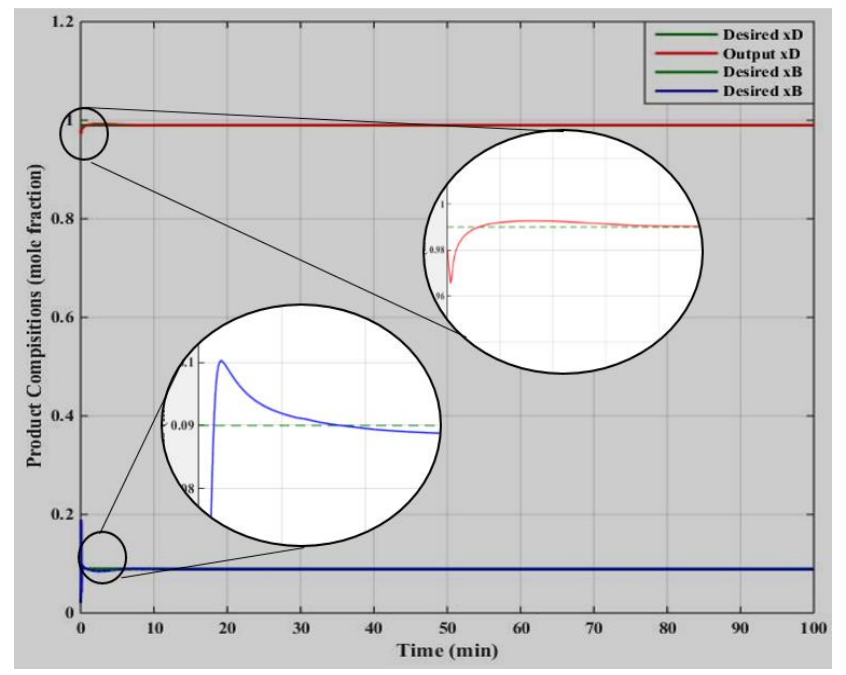

(a)

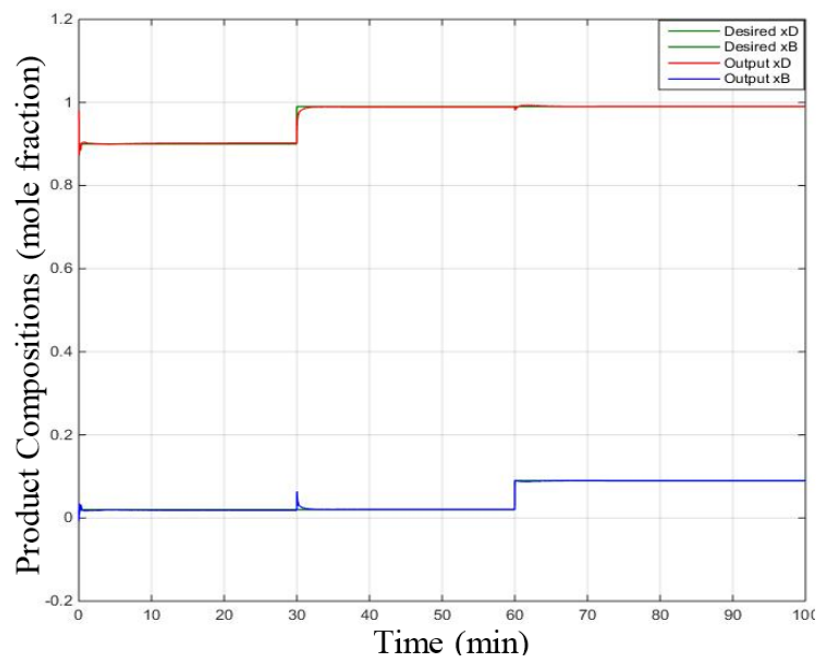

(b)

Fig. 5. Response of distillation column (product compositions): (a) fixedstep; (b) changed-step 
The parameters applied for the optimization, using PSO, are indicated as:

Size of the swarm (no. of birds) 100

Iterations (max) 100

Cognitive acceleration $\quad 1.2$

Social acceleration $\quad 0.12$

Momentum or inertia $\quad 0.9$

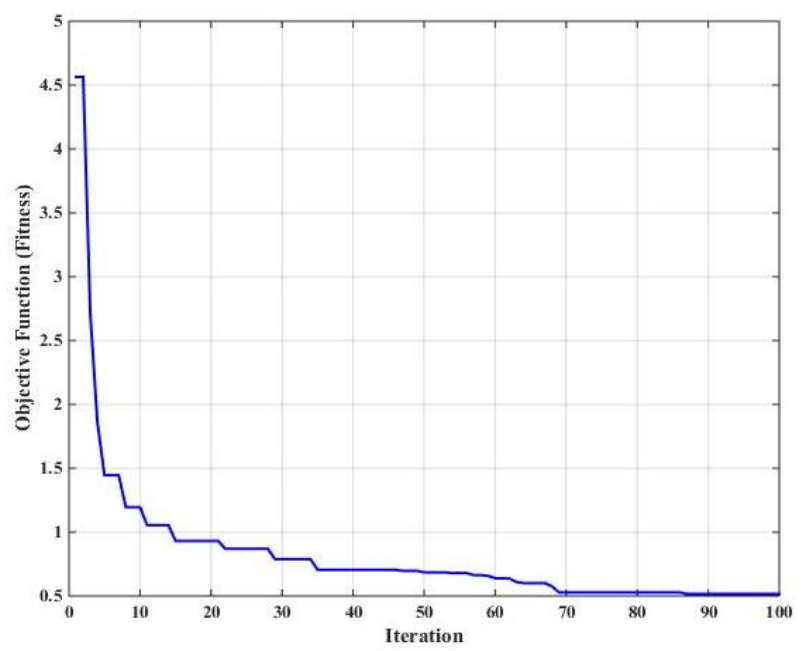

Fig. 6. Objective function convergence of PSO-tuned PD-fuzzy logic control of distillation column

No. of Variables (dimension) 6

The objective function (fitness) convergence of PSO used shown in Fig. 6, with the parameters presented above.

\section{CONCLUSIONS}

This research introduced the PSO based tuning method for PD-fuzzy logic to control the product compositions of distillation column. The scaling factors of fuzzy controller were tuned using this technique. The integral of square error (ISE) between desired and output product compositions were employed in PSO as objective function (fitness). In addition, different set points have been applied to test robustness of the controllers. As a result, the PSO-tuned PD-fuzzy logic controller can achieve good performance and fast response with good deal with external disturbances for controlling both of product compositions of the column. Furthermore, implementation of this controller is much easier than the traditional approaches for the reason that there is no need for derivative knowledge nor complex mathematical equations.

\section{REFERENCES}

[1] B. A. Ogunnaike, "Problems and challenges of industrial process control: A commercial polymerization reactor case study," in Computer-Aided Control System Design, 1994. Proceedings, IEEE/IFAC Joint Symposium On, 1994, pp. 27-36.

[2] M. Mahfouf, S. Kandiah and D. A. Linkens, "Fuzzy model-based predictive control using an ARX structure with feedforward," Fuzzy Sets Syst., vol. 125, pp. 39-59, 2002.

[3] P. N. Q. Nhon, I. Elamvazuthi, H. M. Fayek, S. Parasuraman and M. K. A. A. Khan, "Intelligent Control of Rehabilitation Robot: Auto Tuning PID Controller with Interval Type 2 Fuzzy for DC Servomotor," Procedia Computer Science, vol. 42, pp. 183-190, 2014.

[4] Y. Lu, Industrial Intelligent Control: Fundamentals and Applications. John Wiley \& Sons, Inc., 1996.

[5] R. F. Luo, H. H. Shao and Z. J. Zhang, "Fuzzy-neural-net-based inferential control for a high-purity distillation column," Control Eng. Pract., vol. 3, pp. 31-40, 1, 1995.

[6] J. F. de Canete, T. Cordero, D. Guijas and J. Alarcon, "An adaptive neurofuzzy approach to control a distillation column," Neural Computing \& Applications, vol. 9, pp. 211-217, 2000.

[7] M. Miccio and B. Cosenza, "Control of a distillation column by type-2 and type-1 fuzzy logic PID controllers," J. Process Control, vol. 24, pp. 475-484, 5, 2014.

[8] T. W. Mix, J. Dweck, M. Weinberg and R. Armstrong, Energy Conservation in Distillation. Final Report, 1981.

[9] C. Smith, Distillation Control: An Engineering Perspective. John Wiley \& Sons, 2012.

[10] W. L. Luyben, Distillation Design and Control using Aspen Simulation. John Wiley \& Sons, 2013.

[11] H. Li and H. Gatland, "Conventional fuzzy control and its enhancement," Systems, Man, and Cybernetics, Part B: Cybernetics, IEEE Transactions On, vol. 26, pp. 791-797, 1996.

[12] Y. Zhao and E. G. Collins Jr, "Fuzzy PI control design for an industrial weigh belt feeder," Fuzzy Systems, IEEE Transactions On, vol. 11, pp. 311-319, 2003.

[13] R. R. Yager and D. P. Filev, "Essentials of fuzzy modeling and control," John Wiley \& Sons, Inc., New York, 1994.

[14] S. Chopra, R. Mitra and V. Kumar, "A robust scheme for tuning of fuzzy PI type controller," in Intelligent Systems, 2006 3rd International IEEE Conference On, 2006, pp. 300-305.

[15] J. Hurel, A. Mandow and A. Garcia-Cerezo, "Tuning a fuzzy controller by particle swarm optimization for an active suspension system," in IECON 2012-38th Annual Conference on IEEE Industrial Electronics Society, 2012, pp. 2524-2529.

[16] R. C. Eberhart and J. Kennedy, "A new optimizer using particle swarm theory," in Proceedings of the Sixth International Symposium on Micro Machine and Human Science, 1995, pp. 39-43.

[17] J. Kennedy, J. F. Kennedy and R. C. Eberhart, Swarm Intelligence. Morgan Kaufmann, 2001 